\title{
A STUDY ON STANDARDIZATION AND ASSESSMENT OF SENSORY AND MICROBIOLOGICAL QUALITY OF HERBAL RASAM
}

\author{
VIJAYALAKSHMI S, ARUN A, KANCHANA ARUN* \\ School of Hotel and Catering Management, Vels University, Chennai, Tamil Nadu, India. \\ Email: kanchanaarunarasu@gmail.com
}

Received: 28 April 2017, Revised and Accepted: 11 May 2017

\begin{abstract}
Objective: Herbs have gained a widespread acceptance as a dietary constituent in Tamil Nadu, generally forming a substantial portion of the diet which serves as a therapeutic function. This study was aimed to formulate and standardize the four types of Rasam using four different herbs and to analyze its quality changes in fresh Rasam and refrigerated Rasam $\left(4 \pm 1^{\circ} \mathrm{C}\right)$. Appearance and odor scores of Rasam were satisfactory throughout the storage. Sensory attributes were rated better for fresh Rasam than refrigerated Rasam, but all the attributes were decreased with increasing storage period.
\end{abstract}

Methods: Microbiological quality of four types of different herbal Rasam was examined with freshly prepared Rasam and with refrigerated Rasam for the presence of Escherichia coli, Staphylococcus aureus, Salmonella and Yeast, and Mold.

Result: Comparison with the microbiological results shows in refrigerated Rasam-PAR, SAR, and AIR were at an acceptable level of microbiological quality whereas, Rasam-STR were at an unacceptable level of microbial quality due high level of total plate count and yeast and mold growth. Salmonella was examined, but it was not detected in all the four Rasam. Similarly, the microbial quality of all four freshly prepared Rasam showed highly acceptable. Conductivity was measured for the presence of ions in solution.

Conclusion: This study proposes that to minimize bacterial level in foods and always to consume freshly prepared Rasam than refrigerated. It also concludes that good hygiene practices are necessary though the food serves a therapeutic function.

Keywords: Herbal Rasam, Sensory assessment, Microbial quality, Conductivity.

(C) 2017 The Authors. Published by Innovare Academic Sciences Pvt Ltd. This is an open access article under the CC BY license (http://creativecommons. org/licenses/by/4. 0/) DOI: http://dx.doi.org/10.22159/ajpcr.2017.v10i8.19352

\section{INTRODUCTION}

The cuisine of Tamil Nadu had a traditional system which can be renowned as an antiquated long-established medicinal structure. Tamil Nadu cuisine has a system of recipes which activates and strengthens the inner sources of the body. Many literatures in Tamil defines the food, we consume itself is to be considered medicine. The ingredients and methods used in the preparations of our food have its own medicated value constituting the spices and herbs with therapeutic nature. As per our traditional medicine our food constitutes the herbal spices such as garlic, pepper, curry leaves, mints, cumin seeds, asafoetida, coriander, ginger, and mustard [1]. Rasam compiles the actual motto of our cuisine being prepared constituting the medicinal and therapeutic ingredients. Rasam is a healthy and spicy Indian soup also an important part of meal consumed plain or with rice.

Rasam is an easy and simple dish to prepare. Basically, Rasam is prepared with tamarind and pepper corn as the base, beside many varieties of Rasam are prepared acquiring its name from the chief ingredient used for preparation example tomato Rasam, lemon Rasam, etc., [2].

Rasam has a good therapeutic, and medicinal value - the dietary fibers present in the tamarind helps to lower the cholesterol, detoxify the colon and prevents constipation, potassium reduces blood pressure, and iron improves the hemoglobin value in blood [3]. Garlic an antibacterial relieves digestion and acidity problems; pepper corn upholds urination, cures gastric problems [4]. Depending on the ingredients added to Rasam the therapeutic and medical value of Rasam is enhanced. Rasam has a shelf life of 2-3 days as it is spicily strong [5].
Although Rasam is prepared in different varieties such as tamarind Rasam, lemon Rasam, pepper Rasam, pineapple Rasam, and coriander Rasam all these ingredients as mentioned in Siddha medicine is mostly present in all varieties of Rasam. This can, in fact, be called as an antidote. Rasam has got the ability to fight against tiredness, fatigue, loss of appetite, distaste, flatulence, etc. Rasam truly complies with this motto of Siddha [6].

Rasam is an authentic delicious dish. Many types of Rasam are prepared in Tamil Nadu it acquires its name from the main ingredient used for the preparation.

\section{Objectives of the study}

The following objectives were structured to conduct the study:

- To formulate and standardize the four types of Rasam using four different herbs.

- To analyze its quality changes in fresh Rasam and refrigerated Rasam $\left(4 \pm 1^{\circ} \mathrm{C}\right)$ by sensory evaluation and microbial study.

The purpose of the study was to standardize and assess the sensory and microbiological quality of Herbal Rasam. Four types of herbs have been used for preparing the four different types of Rasam. Herbs used for the study - Herb 1: Solanum trilobatum; Herb 2: Azadirachta indica; Herb 3: Senna auriculata, and Herb 4: Plectranthus amboinicus. Many studies proved that these herbs exhibit phytoconstituents and have emerged as a good source of ethno medicines. All these four herbs are traditionally claimed to possess the significant therapeutic potential to treat various ailments in human. The traditional use of the S. trilobatum as green medicine [7], A. indica as antimicrobial activity [8], S. auriculata as antidiabetic, antihyperlipidemic, and antioxidant effects [9] and P. amboinicus as analgesic and anti-inflammation [10]. 
Using these herbs, four different types of herbal Rasams were formulated and standardized. The standardized four herbal Rasam was coded as Code-PAR, Code-SAR, Code-AIR, and Code-STR. These coded Rasam was evaluated for its sensory attributes and microbial quality.

\section{METHODS}

\section{Selection of the ingredients}

The herbs were purchased from the traditional herbal store, and other ingredients were bought from the local markets. The herbs, tomatoes, coriander, and curry leaves were cleaned and washed.

\section{Preparation of Rasam}

Rasam powder

Peppercorns, cumin seeds, and coriander seeds were roasted together in a pan. This mixture was blended into a fine powder in the mixer.

\section{Standardization of herbal Rasam}

The amount of herbs and spices to be added were determined by first trying out on smaller quantities until they produced desirable sensory effects. The results obtained from these trials were followed for adding the ingredients in the final product of the four types of herbal Rasam (Table 1).

The four types of Rasam were prepared from a combination of four different herbs and common spices depending on the desired result. For Code-PAR Rasam, boiled water was infused over the herb P. amboinicus. One tablespoon of oil was added. Mustard seeds and curry leaves were added when the pan got heated up. This was added with mashed tomatoes and cooked till it formed a paste. The infused herb P. amboinicus along with water content was added into the mixture. Rasam powder was added along with two cups of water and simmered it for 2 minutes. CodePAR - Rasam was removed from the heat just before boiling.

The same procedure was carried out for other three types of herbal Rasam such as Code-SAR, Code-AIR, and Code-STR with the specified amount of spices and other ingredients in the formulation.

\section{Sensory evaluation}

Rasam was prepared and served at Food and Beverage Production Laboratory at School of Hotel and Catering Management, Vels University. 20 faculty members were involved as the panel members. All four freshly prepared herbal Rasam were served and a sensory evaluation form with a structured 5-point rating scale. Similarly, the same panel members analyzed the Rasam for its sensory attributes which were under refrigerated storage during $24 \mathrm{hrs}$. All the sensory attributes of both freshly prepared and refrigerated storage Rasam, scores were rated between 5 and 1, and each score represents as- 5 for very good, 4 for good, 3 for satisfactory, 2 for poor, and 1 for very poor. Rasam was served in a perfect interval of time for an eminent outcome of data.

Evaluation of microbial quality

The four samples of $100 \mathrm{ml}$ of herb Rasam were evaluated for its microbial quality. Assessment of microbial quality was assessed with freshly prepared Rasam and with refrigerated storage Rasam during $24 \mathrm{hrs}$. Aerobic mesophilic counts of all four freshly prepared Rasam and refrigerated storage Rasam such as Code-PAR, Code-SAR, CodeAIR, and Code-STR analyzed for total microbial count, Salmonella, Staphylococcus aureus, Escherichia coli, and Yeast, and Mold.

\section{pH value of Rasam}

The $\mathrm{pH}$ value of the herbal Rasam was calculated using the litmus paper to check the acidic value of the Rasam freshly prepared Rasam and after 24 hrs refrigerated storage Rasam.

\section{Conductivity}

The measurement of conductivity is a rapid and inexpensive way of determining the ionic strength of a solution. However, it is a nonspecific technique, unable to distinguish between different types of ions, giving instead a reading that is proportional to the combined effect of all the ions present in the standardized herbal Rasam.

\section{Statistical analysis}

Data collected from the panel members were analyzed for mean score and standard deviation using SPSS (21.0) software.

\section{RESULTS AND DISCUSSION}

\section{Sensory attributes of herbal Rasam}

The appearance scores for all four herbal Rasam showed (Table 2) decreasing trend in refrigerated storage (after $24 \mathrm{hrs}$ ). In refrigerated storage, appearance scores of Rasam decreased significantly $(\mathrm{p}<0.05)$ after $24 \mathrm{hrs}$ on 5 -point scale. The appearance scores of all four herbal Rasam were at satisfactory level after the storage period of $24 \mathrm{hrs}$ storage without marked deterioration.

Flavor scores of all four coded fresh Rasam were showed significantly higher than that of refrigerated Rasam after $24 \mathrm{hrs}$ in refrigerated storage. Higher flavor of freshly prepared Rasam was due to the use of fresh ingredients. Rasam flavor declined gradually and significantly $(p<0.01)$ in refrigerated storage on each hour (Tables 2). A gradual decline in flavor scores of stored Rasam might be due to loss of volatile flavor components from spices and condiments. It might also be due to

Table 1: Recipe formulation and standardization of Rasam Code-PAR/Code-SAR/Code-AIR/Code-STR (100 ml)

\begin{tabular}{lllll}
\hline \multirow{2}{*}{ Ingredients } & \multicolumn{2}{l}{ Quantity } \\
\cline { 2 - 5 } & \multicolumn{2}{l}{ Code-PAR } & Code-SAR & Code-AIR Code-STR \\
\hline Tomato (g) & 50 & 50 & 50 & 50 \\
Turmeric powder (g) & 2 & 2 & 2 & 2 \\
Chili powder (g) & 5 & 5 & 5 & 5 \\
Crushed pepper (g) & 5 & 5 & 5 & 5 \\
Coriander powder (g) & 5 & 5 & 5 & 5 \\
Curry leaves (g) & 5 & 5 & 5 & 5 \\
Coriander leaves (g) & 5 & 5 & 5 & 5 \\
Mustard seeds (g) & 2 & 2 & 2 & 2 \\
Oil (ml) & 20 & 20 & 20 & 20 \\
Cumin seeds (g) & 5 & 5 & 5 & 5 \\
Karpooravalli leaves (g) & 10 & - & - & - \\
Avarampoo (g) & - & 10 & - & - \\
Neem flower (g) & - & 0 & 10 & - \\
Thoothuvalai poo (g) & - & - & - & 10 \\
\hline
\end{tabular}

Table 2: Sensory scores of freshly prepared Rasam and refrigerated Rasam

\begin{tabular}{|c|c|c|}
\hline Parameter & Freshly prepared & $\begin{array}{l}\text { Refrigerated Rasam }\left(4 \pm 1^{\circ} \mathrm{C}\right. \\
\text { and after } 24 \mathrm{hrs})\end{array}$ \\
\hline \multicolumn{3}{|l|}{ Appearance } \\
\hline Code-PAR & $4.53 \pm 0.18$ & $3.03 \pm 0.11$ \\
\hline Code-SAR & $4.67 \pm 0.24$ & $3.32 \pm 0.30$ \\
\hline Code-AIR & $4.15 \pm 0.32$ & $3.01 \pm 0.29$ \\
\hline Code-STR & $4.28 \pm 0.92$ & $3.05 \pm 0.27$ \\
\hline \multicolumn{3}{|l|}{ Flavor } \\
\hline Code-PAR & $4.43 \pm 0.11$ & $2.03 \pm 0.07$ \\
\hline Code-SAR & $4.60 \pm 0.31$ & $2.27 \pm 0.12$ \\
\hline Code-AIR & $4.23 \pm 0.31$ & $3.01 \pm 0.93$ \\
\hline Code-STR & $4.05 \pm 0.29$ & $2.11 \pm 0.10$ \\
\hline \multicolumn{3}{|l|}{ Flavor } \\
\hline Code-PAR & $4.12 \pm 0.11$ & $4.37 \pm 0.07$ \\
\hline Code-SAR & $4.63 \pm 0.31$ & $4.42 \pm 0.12$ \\
\hline Code-AIR & $4.22 \pm 0.31$ & $4.02 \pm 0.93$ \\
\hline Code-STR & $4.13 \pm 0.29$ & $3.88 \pm 0.10$ \\
\hline \multicolumn{3}{|l|}{ Palatability } \\
\hline Code-PAR & $4.12 \pm 0.11$ & $2.09 \pm 0.07$ \\
\hline Code-SAR & $4.63 \pm 0.31$ & $3.17 \pm 0.12$ \\
\hline Code-AIR & $4.22 \pm 0.31$ & $2.02 \pm 0.93$ \\
\hline Code-STR & $4.13 \pm 0.29$ & $3.05 \pm 0.10$ \\
\hline
\end{tabular}


initiation of lipid oxidation in stored Rasam. Flavor of Rasam remained poor and unsatisfactory in the refrigerated storage Rasam. However, no off-flavor was detected by panellists in the $24 \mathrm{hrs}$ refrigerated storage period of Rasam.

Consistency of stored and fresh Rasam did not differ significantly $(p>0.05)$. Consistency scores of Rasam decreased significantly $(p<0.05)$ with increasing refrigerated storage and panellists preference was good only.

Overall palatability of Rasam, panellists significantly $(\mathrm{p}<0.01)$ preferred the fresh Rasam compared to stored Rasam (Table 2). This could be due to the contribution of fresh ingredients on sensory attributes especially flavored. However, overall palatability scores were marked higher for freshly prepared Rasam and declined significantly in refrigerated storage Rasam and the scores showed by the panellists was poor only.

Biochemical changes brought about by microorganisms and chemical reactions occurring in the product, refrigerated storage Rasam might have contributed for decline in scores of difference in sensory attributes of Rasam during storage period. All the sensory attributes of both the freshly prepared and refrigerated storage Rasam were rated between 5 and 1 and each score represents as - 5 for very good, 4 for good, 3 for satisfactory, 2 for poor, and 1 for very poor.

\section{Appearance and odor score: Five-point scale adopted} pH freshly prepared Rasam and refrigerated Rasam

$\mathrm{pH}$ of the refrigerated Rasam as well as freshly prepared Rasam was not showed a significant difference $(p>0.05)$ and remained almost same throughout the storage period of $24 \mathrm{hrs}$ refrigerated storage (Table 3 ).

\section{Microbial quality of herbal Rasam}

Aerobic mesophilic counts of all four freshly prepared Rasam such as PAR, SAR, AIR, and STR and refrigerated Rasam was lower to be categorized as satisfactory and within acceptable limit for assuring food safety. All four stored refrigerated Rasam had significantly $(\mathrm{p}<0.01)$ higher microbial counts than freshly made Rasam. Microbial counts were not detected in all four freshly prepared Rasam might be due to fresh preparation in well-sanitized equipment, and Rasam was cooked thoroughly at boiling temperature. Furthermore, high-level food safety and personal hygiene were maintained which microbial counts were unable to detect in freshly prepared Rasam. Aerobic mesophilic count showed gradual increasing trend with the advancement of refrigerated storage period. Absence of Salmonella genus might be due to thermal processing and better sanitary measures adopted during processing of Rasam (Table 4).

Yeast and Mold growth were observed in refrigerated storage Rasam. However, Yeast and Mold growth were not observed in freshly prepared Rasam.

\section{Conductivity}

Measuring conductivity simply detects the presence of ions in solution and is, therefore, a non-specific measurement. In general, the measurement of conductivity is a rapid and inexpensive way of determining the ionic strength of a solution (Conductivity Theory and Practice- Booklet). The total concentration of ions in all four Rasam, such as Code-PAR, Code-SAR, Code- AIR, and Code-STR was measured and obtained the results as given Table 5 .

\section{CONCLUSION}

Traditional use of herbal based diet implies substantial historical use, and this is certainly true for many recipes based on herbs used. In many developing countries, a large proportion of the population relies on traditional and herbal based diet. Rasam is prepared mainly with tamarind or tomato as the base along with cumin, black pepper, and dry chili powder as flavoring ingredients. All of these ingredients are abundant in South India. Herbal Rasam can be eaten with rice or separately as a spicy soup. In a meal, it can be part of a course on a
Table 3: Effect of refrigeration storage on $\mathrm{pH}$

\begin{tabular}{lll}
\hline $\mathbf{p H}$ & Freshly prepared & $\begin{array}{l}\text { Refrigerated Rasam }\left(\mathbf{4} \pm \mathbf{1}^{\circ} \mathbf{C} \text { and }\right. \\
\text { after } \mathbf{2 4} \mathbf{~ h r s})\end{array}$ \\
\hline Code-PAR & $5.53 \pm 0.01$ & $5.16 \pm 0.11$ \\
Code-SAR & $5.07 \pm 0.14$ & $5.05 \pm 0.10$ \\
Code-AIR & $5.15 \pm 0.02$ & $5.01 \pm 0.12$ \\
Code-STR & $5.80 \pm 0.12$ & $5.11 \pm 0.21$ \\
\hline
\end{tabular}

Table 4: Effect of refrigeration storage on microbiological quality

\begin{tabular}{|c|c|c|c|}
\hline Microbial quality & Units & $\begin{array}{l}\text { Freshly } \\
\text { prepared }\end{array}$ & $\begin{array}{l}\text { Refrigerated } \\
\text { Rasam }\left(4 \pm 1^{\circ} \mathrm{C}\right. \\
\text { and after } 24 \mathrm{hrs})\end{array}$ \\
\hline \multicolumn{4}{|l|}{ Code-PAR } \\
\hline Total plate count & $\mathrm{CFU} / \mathrm{g}$ & ND & 100 \\
\hline Staphylococcus aureus & $\mathrm{CFU} / \mathrm{g}$ & ND & $<10$ \\
\hline Salmonella & Per $25 \mathrm{~g}$ & ND & Absent \\
\hline Escherichia coli & $\mathrm{CFU} / \mathrm{g}$ & ND & $<10$ \\
\hline Yeast and Mold & $\mathrm{CFU} / \mathrm{g}$ & ND & $<10$ \\
\hline \multicolumn{4}{|l|}{ Code-SAR } \\
\hline Total plate count & $\mathrm{CFU} / \mathrm{g}$ & ND & 300 \\
\hline Staphylococcus aureus & CFU/g & ND & $<10$ \\
\hline Salmonella & Per $25 \mathrm{~g}$ & ND & Absent \\
\hline Escherichia coli & $\mathrm{CFU} / \mathrm{g}$ & ND & $<10$ \\
\hline Yeast and Mold & $\mathrm{CFU} / \mathrm{g}$ & ND & $<10$ \\
\hline \multicolumn{4}{|l|}{ Code-AIR } \\
\hline Total plate count & $\mathrm{CFU} / \mathrm{g}$ & ND & 400 \\
\hline Staphylococcus aureus & $\mathrm{CFU} / \mathrm{g}$ & ND & $<10$ \\
\hline Salmonella & Per $25 \mathrm{~g}$ & ND & Absent \\
\hline Escherichia coli & $\mathrm{CFU} / \mathrm{g}$ & ND & $<10$ \\
\hline Yeast and Mold & $\mathrm{CFU} / \mathrm{g}$ & ND & 200 \\
\hline \multicolumn{4}{|l|}{ Code-STR } \\
\hline Total plate count & $\mathrm{CFU} / \mathrm{g}$ & ND & 5300 \\
\hline Staphylococcus aureus & $\mathrm{CFU} / \mathrm{g}$ & ND & $<10$ \\
\hline Salmonella & Per $25 \mathrm{~g}$ & ND & Absent \\
\hline Escherichia coli & $\mathrm{CFU} / \mathrm{g}$ & ND & $<10$ \\
\hline Yeast and Mold & $\mathrm{CFU} / \mathrm{g}$ & ND & 300 \\
\hline
\end{tabular}

Table 5: Conductivity in herbal Rasam

\begin{tabular}{ll}
\hline Conductivity & Freshly prepared $\boldsymbol{\mu s} / \mathbf{c m}$ \\
\hline Code-PAR & 16070 \\
Code-SAR & 27530 \\
Code-AIR & 26450 \\
Code-STR & 26590 \\
\hline
\end{tabular}

regular diet. In this research project, four different herbs have been sued such as S. trilobatum, A. indica, S. auriculata, and P. amboinicus. Using these herbs, four different types of herbal Rasam were formulated and standardized. These herbs are medicinal plants meet health care needs of every individual and when it is incorporated in the recipes as a functional ingredient on their routine diet helps to maintain their health and also prevent lifestyle-related diseases.

\section{ACKNOWLEDGMENT}

We wish to express our sincere appreciation to the Final year Hotel and Catering Management students for preparing the Rasams and arranging to have the samples tasted by the respondents.

\section{REFERENCES}

1. Live Chennai.com. Untold Benefits of Rasam. [Last updated on 2015 Sep 15; Last cited on 2017 Apr 15].

2. Shankar P. Rasam Recipes-South Indian Rasam Recipes-Rasam Varieties-Rasam Recipe (Tamil) Padhus Kitchen. Available from: http://www.padhuskitchen.com/2010/10/rasam-recipes-south-indianrasam.html. [Last cited on 2017 Apr 15]. 
3. Maheshwari RK, Jat BL, Khan S, Rajnee MM, Chaudhary U. To demystify savory Tamarindus indica Linn. For healthcare. Int J Pharm Nat Med 2014;2(2):173-9.

4. Thumma S. Everything about RASAM. Available from: https://www. vahrehvah.com/indianfood/rasam. [Last cited on 2017 Apr 18].

5. Santhamohan P. Tomato Rasam Recipe|Thakkali Rasam. Available from: http://www.asmallbite.com/tomato-rasam-recipe-thakkali-rasam. [Last updated on 2016 Nov 21; Last cited on 2017 Apr 18].

6. Rasam. Available from: https://www.en.wikipedia.org/wiki/Rasam. [Last updated on 2017 Mar 25; Last cited on 2017 Apr 02].

7. Doss A, Mubarack HM, Dhanabalan R. Antibacterial activity of tannins from the leaves of Solanum trilobatum Linn. And science. Indian J Sci
Technol 2009;2(2):41-3

8. Susmitha S, Vidyamol KK, Ranganayaki P, Vijayaragavan R. Phytochemical extraction and antimicrobial properties of Azadirachta indica (neem). Glob J Pharmacol 2013;7(3):316-20.

9. Shanmugasundaram R, Devi VK, Soris PT, Maruthupandian A, Mohan VR. Antidiabetic, antihyperlipidaemic and antioxidant activity of Senna auriculata (L.) Roxb. Leaves in alloxan induced diabetic rats. Int J PharmTech Res 201;3(2):747-75.

10. Chiu YJ, Huang TH, Chiu CS, Lu TC, Chen YW, Peng WH, et al. Analgesic and anti inflammatory activities of the aqueous extract from Plectranthus amboinicus (Lour.) Spreng. Both in vitro and in vivo. Evid Based Complement Alternat Med 2012;2012:11. 